\title{
O TRABALHO DE MÉDICOS ONCOLOGISTAS: EVIDÊNCIAS PSICODINÂMICAS DE PRAZER E SOFRIMENTO OCUPACIONAL
}

\author{
WORK OF ONCOLOGISTS: \\ PSYCHODYNAMIC EVIDENCES OF OCCUPATIONAL PLEASURE AND SUFFERING
}

\author{
MARISNEI SOUZA DOURADO \\ Centro Universitário Unihorizontes \\ Mestre em Administração \\ Orcid: http://orcid.org/0000-0003-1218-337X \\ E-mail: marisnei.dourado@mestrado.unihorizontes.br \\ Endereço: Rua Alves Martins 78/201 - Calafate \\ CEP 30.411-510 - Belo Horizonte - MG \\ LUIZ CARLOS HONÓRIO \\ Professor do Mestrado Acadêmico em Administração - Centro Universitário Unihorizontes \\ Doutor em Administração CEPEAD/FACE/UFMG \\ Orcid: http://orcid.org/ 0000-0001-8345-2587 \\ E-mail: luiz.honorio@unihorizontes.br
}

\begin{abstract}
RESUMO
$\mathrm{O}$ artigo tem como objetivo descrever elementos psicodinâmicos que configuram o contexto de trabalho e as vivências de prazer e sofrimentos pertinentes ao ambiente ocupacional de médicos oncologistas que atuam em hospitais e clínicas localizadas em Belo Horizonte, Minas Gerais. A metodologia possui abordagem qualitativa, recorrendo-se ao uso de entrevistas estruturadas, tendo os dados sido submetidos à análise de conteúdo para fins de definição de unidades de registro e categorias de tratamento. A análise apontou que as vivências de prazer estão associadas à realização no trabalho; à liberdade para expressar opiniões, ao relacionamento estabelecido entre pares e chefia e às condições físicas do ambiente de trabalho. Como elementos de sofrimento foram evidenciados o esgotamento profissional, a falta de organização no atendimento do paciente, a insegurança no trabalho e a sobrecarga emocional. Aspectos associados à organização do trabalho, por exemplo, ritmo intenso funcional e cobrança por resultados também foram mencionados como desencadeadores de sofrimento no trabalho. Em consonância com os pressupostos teóricos do artigo, revelou-se que o contexto de trabalho pesquisado está caracterizado por elementos estruturantes e desestruturantes que podem surtir efeitos tanto favoráveis quanto desfavoráveis à saúde física e psíquica, levando o oncologista a experimentar, indissociavelmente, vivências de prazer e sofrimento.
\end{abstract}

Palavras-chave: Psicodinâmica do trabalho. Prazer no trabalho. Sofrimento no Trabalho .

Data de submissão: 28/03/2018. Data de aceite: 04/08/2019. Data de publicação: 13/08/2019. 


\begin{abstract}
The article aims to describe psychodynamic elements that configure the work context and experiences of pleasure and suffering concerning to the occupational environment of oncologists who work in hospitals and clinics located in Belo Horizonte, Minas Gerais. The methodology was qualitative and one used structured interview. Moreover, the data was subjected to content analysis in order to define the treatment of register units and categories. The analysis pointed out that the experiences of pleasure are associated to professional fulfillment; to freedom to express one's opinions, to the relationships established between colleagues and management levels and to the physical conditions of work environment. The elements evidenced as suffering factors were professional burnout, the lack of organization during patient care, job insecurity and emotional overload. In addition, aspects associated to labor organization, such as intense work rhythm and accountability for results were also mentioned as factors that trigger work suffering. In accordance with the theoretical assumptions of the article, it was revealed that the researched work context is characterized by structuring and de-structuring elements that can cause both favorable and unfavorable effects to physical and psychological health, carrying the oncologist to experiment, inseparably, pleasure and suffering experiences.
\end{abstract}

Keywords: Psychodynamics of work. Work Pleasure. Work Suffering.

\title{
1 INTRODUÇÃO
}

A literatura revela que o trabalho, além de transcender o âmbito da economia, é um elemento balizador da experiência humana, uma vez ser considerado essencial para a formação do indivíduo, o estabelecimento de normas sociais relativas aos deveres e direitos percebidos no exercício da função laboral e o alcance de resultados tanto profissionais quanto sociais. $O$ trabalho faz também com que o indivíduo se sinta parte da sociedade e seguro quanto ao uso que se faz do produto da sua atividade. Portanto, a vinculação do indivíduo ao trabalho é considerada central na constituição do sujeito que pensa, sente, age e, a partir dessas ações, cria identidade social, pessoal e ocupacional (HISCHFELD; FEILD, 2000; MORIN, 2001; TOLFO; PICCININI, 2007; BENDASOLLI; BORGES-ANDRADE, 2011; KUBO; GOUVÊA, 2012; BENDASOLLI; ALVES; TORRES, 2014; DERANTY, 2015; POLOMENI, 2015).

Por apresentar a condição de ser central na vida do indivíduo, o trabalho pode ser tratado tanto como eixo construtor do ser humano quanto como fator desencadeador de doenças, isto é, se constituir em fonte de prazer e/ou de sofrimento. Ressalta-se que as vivências de prazer e de sofrimento associadas ao trabalho resultam da história individual de cada trabalhador e de seu contato com a organização do trabalho (DEJOURS, 2012). Dito de outro modo, as condições de historicidade e práticas associadas ao trabalho fazem com que alguns trabalhadores se sucumbam a determinadas doenças e outros não (DEJOURS; DERANTY, 2010).

A díade 'prazer e sofrimento' representa um núcleo importante na Psicodinâmica do Trabalho (DEJOURS, 2014), cujos estudos a respeito dessa abordagem apontam que a rigidez do modelo de organização do trabalho influencia negativamente no processo psíquico dos indivíduos, denotando-se que divergências entre as necessidades do sistema corpo-mente e a impossibilidade de atendimento a essas demandas desencadeiam sofrimento psíquico característico de cada categoria profissional (LIMA JÚNIOR; CASTANHA, 2011; MARTINS; 
HONÓRIO, 2014; DUARTE; MENDES, 2015). Todavia, admite-se a existência de categorias mais susceptíveis ao adoecimento no trabalho, como parece ser o caso dos médicos oncologistas.

Quando se trata da realidade brasileira, o Instituto Nacional de Câncer José Alencar Gomes da Silva (INCA) informou que no Brasil eram estimados para 2016/2017 aproximadamente 496.070 mil novos casos de câncer, incluindo os casos de pele não melanoma. Em Minas Gerais, âmbito tratado neste artigo, a estimativa do INCA girava em torno de quase $60,0 \%$ desse total, perfazendo o número de 291.090 mil novos casos de câncer, incluindo todas as neoplasias. Ou seja, o estado de Minas Gerais ocupava o primeiro lugar nas estimativas no último relatório publicado pelo INCA. Assim, este assunto vem sendo tratado como um problema de saúde pública, significando dizer que a prevenção e o controle da doença deverão ser priorizados em todas as regiões do país, não importando o nível de desenvolvimento em que se encontram (INCA, 2016).

Acrescenta-se que o câncer é considerado uma das doenças mais temidas pelos seres humanos, em função do mau prognóstico que acarreta e dos tratamentos que invariavelmente causam reações adversas, tanto de ordem física quanto emocional. No que tange aos profissionais que exercem a medicina oncológica destaca-se que eles cuidam de um tipo de enfermidade que requer um tratamento longo com várias internações e procedimentos ambulatoriais, resultando em maior proximidade com o paciente e seus familiares (CANO, 2014). Além disso, o oncologista é constantemente conduzido a rever suas crenças e seus valores em relação à doença, a acompanhar novas possibilidades terapêuticas e a lidar rotineiramente com a vida e morte dos pacientes (FLAUZINO, 2012; CANO; MORÉ, 2016).

Exige-se do oncologista uma série de habilidades que incluem o domínio de tecnologias aprimoradas, a autonomia, o dinamismo, o discernimento, a agilidade, a comunicação e a capacidade de solucionar problemas atrelados ao câncer (MAGER; ANDRYKOWSKI, 2002; SALANDER, 2002; SHANAFELT; DYRBYE, 2012; RODENBACH et al., 2016). Somam-se a estas exigências, idiossincrasias da saúde pública hospitalar brasileira, por exemplo, a superlotação dos serviços, o ritmo acelerado de trabalho e a baixa remuneração dos profissionais. Não obstante a relevância dessas considerações acrescentase que as publicações a respeito da Psicodinâmica do Trabalho de médicos oncologistas são escassas na realidade brasileira (SIMÕES, 2016; RODRIGUES; HONÓRIO, 2016; BRUGNARA; HONÓRIO, 2017; CUNHA; HONÓRIO, 2017).

Reconhece-se que os elementos a respeito da prática oncológica, além de inevitáveis e ubíquos, sejam estimuladores do sofrimento, devendo ser investigados e gerenciados em proveito da saúde e da minimização dos riscos de adoecimento no trabalho (LIMA JÚNIOR; CASTANHA, 2011). Além disso, os poucos registros nacionais encontrados sobre a psicodinâmica do trabalho do médico oncológico estimulam este estudo a preencher essa lacuna empírica por meio do objetivo de descrever, em profundidade, os elementos que caracterizam o contexto de atuação desse profissional, os custos associados à profissão, as vivências ocupacionais de prazer e sofrimento experimentadas no exercício da função e os danos que dela decorrem. 


\section{PSICODINÂMICA DO TRABALHO: PRAZER, SOFRIMENTO E MECANISMOS DEFENSIVOS}

A Psicodinâmica do Trabalho é uma abordagem desenvolvida nos anos 1990 pelo psiquiatra e psicanalista francês Christophe Dejours, cujo foco de investigação orientava-se para os constrangimentos causados pela organização do trabalho sobre o funcionamento psíquico dos trabalhadores. Os estudos iniciais realizados não demonstraram elementos de adoecimento na maioria dos trabalhadores, mas sim fatos apontando que mesmo em contextos extremamente precários e desenvolvendo tarefas repetitivas e pouco significativas eles manifestavam um estado de normalidade que prevalecia ao do adoecimento (DEJOURS, 2000).

A normalidade, segundo argumenta Dejours (2011), não dizia respeito necessariamente a um estado saudável, mas sim a uma condição que podia representar um desequilíbrio entre as forças de trabalho desestabilizadoras do sujeito e os esforços que esse dispendia para conter o sofrimento ocupacional e, assim, evitar a descompensação. Portanto, o equilíbrio previne o não-adoecimento, mas este processo não pode ser considerado saúde, significando dizer que a aparente "normalidade" na qual parece viver a maioria dos trabalhadores converte-se em uma categoria que merece ser estudada. Por conseguinte, o objeto da psicodinâmica implica as interações dinâmicas observadas entre a organização do trabalho e os métodos de subjetivação manifestados pelas vivências de prazer e sofrimento, bem como pelas estratégias de ação para lidar com as contradições da organização do trabalho (DEJOURS, 2011).

O objetivo da psicodinâmica, então, passa a ser a ação individual e coletiva no campo da produção e das relações sociais. À medida que o trabalhador procura elaborar o sofrimento a partir de cada dificuldade ocupacional que enfrentar, ele desenvolverá o sentimento de fortalecimento psíquico, podendo a partir desse lugar experimentar bemestar nas atividades que realiza. Portanto, elementos de prazer e sofrimento se coabitam no espaço de trabalho ocupado por um indivíduo. Tais elementos são discutidos na sequência (DEJOURS, 2014).

O prazer é considerado pela psicodinâmica do trabalho como um princípio mobilizador que conduz o indivíduo a agir para obter autonomia, gratificação, realização e reconhecimento no trabalho que realiza. Então, o prazer se expressa por meio de vivências, fontes, fatores e indicadores de bem-estar no trabalho capazes de promover a estruturação psíquica, a identidade e a manifestação da subjetividade. Portanto, ele é mobilizado por experiências individuais e coletivas com o intuito de ressignificação do sofrimento e da relação estabelecida com o trabalho, devendo-se reiterar a indissociabilidade que caracteriza tais vivências (DEJOURS, 2011).

O prazer, além de ser a capacidade renovada do trabalhador de se adaptar às situações mutáveis da existência sem se afligir, é, também, resultante do funcionamento equilibrado e coerente do ser humano em seus aspectos físicos e psicológicos (MENDES; MULLER, 2013). Ele é mobilizado subjetivamente por meio de três componentes: a inteligência, a discussão e a coletividade, reiterando-se que assim acontece para que o trabalhador se sinta reconhecido pelo que realiza. Significa dizer que o sentimento de reconhecimento se produz pelo julgamento da contribuição dada pelo sujeito à organização do trabalho, via chamada de utilitária, ou pela capacidade de ele criar um trabalho belo, elegante, bonito e original, via denominada por estética. Os conferentes desses tipos de 
reconhecimento são os chefes, os pares, os subordinados e os clientes, enfim, os beneficiários internos e externos da qualidade do trabalho produzido (DEJOURS, 2012).

A autonomia experimentada no exercício de uma atividade ou profissão também é um importante indicador de prazer no trabalho, como também um evento que aspira tornar a atividade ocupacional mais rica, satisfatória e, consequentemente, mais central para o executante (SHARABI; HARPAZ, 2010). Para o trabalhador, a possibilidade de alterar as prescrições das tarefas ou se adequar a elas, de modo que possa ter controle sobre o que realiza, produz a autonomia (CARVER; SCHEIER, 2000; MAGGI, 2016). Sobre este ponto, Dejours (2012) afirma que há um engajamento subjetivo do trabalhador entre as prescrições e o real do trabalho, uma vez que, caso ele fosse meramente mecanizado, poderia ser relegado completamente à máquina. A realidade não se passa obrigatoriamente assim porque elementos espontâneos, imprevisíveis e acidentais contornam o mundo laboral. Dizse que uma organização de trabalho flexível é aquela que favorece o uso da liberdade individual para se fazer as próprias escolhas e transformá-las em capacidade criativa e inovação (CARVER; SCHEIER, 2000). Sob outro ponto de vista, exercitar a autonomia também pode expressar a luta do trabalhador contra a dominação e alienação, haja vista o antagonismo que usualmente se observa entre os desejos pessoais e as prescrições ditadas pela organização do trabalho (DEJOURS, 2006; LALLEMENT, 2015).

Entretanto, é possível que o trabalho não funcione como um elemento de satisfação dos desejos individuais. A viabilidade de se vivenciar essa realidade pode conduzir um indivíduo a não perceber significado no que realiza (DEJOURS, 2012) e, em agravante, experimentar sofrimento, riscos psicossociais (LASCAR, 2014) e descompensações psicopatológicas, por exemplo, desordens sexuais, solidão e assédio (GERNET, 2016). Invariavelmente, a divisão e padronização das tarefas, a rigidez hierárquica, o baixo envolvimento na tomada de decisão, a pouca liberdade criativa, a subutilização da competência técnica e a ausência de reconhecimento, ou seja, elementos decorrentes da organização do trabalho, estão entre as principais fontes de sofrimento ocupacional (DEJOURS, 2012).

Argumenta-se que se a história do sujeito, perpassada por sonhos, desejos, necessidades e projetos de realização profissional não se respaldar naquilo que uma organização pode lhe oferecer, tal condição pode resultar em sofrimento (GAULEJAC, 2008). 0 trabalhador normalmente não percebe conscientemente que o sofrimento possa estar ligado ao trabalho, mesmo que o expresse em comportamentos e atitudes. Ele é sentido sob a forma de drama, materializando-se por meio: a) das imposições que impedem o estabelecimento da identidade e da autonomia no ato de trabalhar livremente; b) da destruição dos recursos sociais fundamentais para o exercício da coletividade, por exemplo, cooperação, solidariedade, confiança e intersubjetividade (BOYER, 2015). Este tipo de vivência mobiliza o sujeito em busca de saúde que, se não for possível ser alcançada em sua plenitude, é sublimada pela necessidade constante de se manter a normalidade no trabalho (DEJOURS, 2012).

Estudos realizados na realidade brasileira evidenciaram que sentimentos de medo, insatisfação, insegurança, estranhamento, desorientação, impotência diante de incertezas, alienação, vulnerabilidade, frustração, inquietação, angústia, depressão, tristeza, agressividade, impotência para promover mudanças, desgaste físico e emocional, desvalorização, culpa, tensão e raiva, destacaram-se como as vivências de sofrimento mais recorrentes no trabalho (LIMA JÚNIOR; CASTANHA, 2011; MARTINS; HONÓRIO, 2014; 
BARROS; HONÓRIO, 2015; DUARTE; MENDES, 2015; SILVA; GONÇALVES, ZONATTO, 2017). Tais sentimentos, somados à precarização do trabalho, ao desemprego estrutural e à luta pela sobrevivência, tornaram o trabalhador enfraquecido e impedido de constituir coletivos, inclusive o familiar (BENDASOLLI, 2011), como também submisso às imposições do mercado (FRANCO; DRUCK; SELINGMANN-SILVA, 2010).

O sofrimento para Dejours (2012) integra o ato de trabalhar, já que a experiência do trabalho inclui o fracasso, os acidentes, os imprevistos, o medo, a insegurança, elementos tais que, inclusive, fazem o trabalhador resistir e encontrar as soluções para superá-los. Por essa razão, o autor alega que não se deve eliminar o sofrimento do trabalho, sob pena de que tal tentativa retiraria do trabalhador a possibilidade de exercitar a capacidade de ser inventivo e inteligente para dissolver os conflitos derivados da lacuna existente entre o trabalho prescrito (a tarefa) e o trabalho real (a atividade). Não obstante a aceitação da pertinência desse argumento, é possível investir em estratégias defensivas para evitar os pesares decorrentes do trabalho ou transformá-los em fonte de prazer (DEJOURS; DERANTY, 2010; MAGNUS; MERLO, 2012).

As estratégias de defesa são recursos utilizados pelos trabalhadores, nas formas individual e coletiva, para diminuir a carga de tensão no trabalho. As estratégias individuais implicam a minimização do sofrimento via a satisfação de necessidades internas, enquanto as estratégias coletivas visam a manutenção do equilíbrio ocupacional por meio de um acordo estabelecido entre os membros do grupo com o intuito de confrontar aquilo que os fazem sofrer. As estratégias coletivas parecem ser mais eficazes do que as individuais por implicarem a adesão e a força grupal. Deve-se aqui fazer uma distinção entre estratégias e mecanismos de defesa. As estratégias de defesa são construídas conscientemente pelo trabalhador para lidar com as idiossincrasias características da organização do trabalho que porventura sejam causadores de sofrimento, enquanto que os mecanismos de defesa se referem aos dispositivos interiorizados pelos indivíduos com o propósito de proteger a integridade do ego sendo, portanto, mobilizados de forma inconsciente (DEJOURS; ABDOUCHELI; JAYET, 1994).

As estratégias podem ser de proteção, adaptação e exploração, sugerindo existir um encadeamento entre elas, em que cada um desses tipos acomoda diferentes mecanismos de defesa. Inicialmente o empregado faz uso de estratégias de proteção, que se assentam no mecanismo da racionalização, que se constitui por modos de pensar, sentir e agir utilizados para suportar ou compensar o elemento causador do sofrimento. Posteriormente, o trabalhador recorre a estratégias de adaptação e, por fim, a estratégias de exploração, ambas se fundamentando no mecanismo da negação, ou seja, na submissão do desejo aos objetivos da organização (MORAES, 2013). Além da racionalização e negação destacam-se como mecanismos defensivos a anulação, o deslocamento, a introjeção, a projeção, a formação reativa, a idealização entre outros (CANÇADO; SANT'ANNA, 2013).

$\mathrm{Na}$ dinâmica organizacional, as estratégias de defesa permitem a convivência com o sofrimento, mas também podem conduzir à alienação da sua verdadeira causa. Tratam-se de recursos elaborados pelos trabalhadores com a finalidade de se manter no trabalho. Ou seja, eles protegem a atividade psíquica, mas não promovem a emancipação porque não implicam uma mobilização capaz de transformar da realidade provocadora do sofrimento. Portanto, favorecem a adaptação do trabalhador à organização do trabalho, fato que, ao longo do tempo, pode conduzi-lo à alienação ou ao agravamento do sofrimento (DEJOURS; ABDOUCHELI; JAYET, 1994). 
Conforme salientado anteriormente os mecanismos de defesa por serem interiorizados são mobilizados pelos indivíduos de forma inconsciente, devendo-se por essa razão, interpretar o conteúdo de seus discursos para se chegar ao entendimento de quais mecanismos espelham as estratégias usualmente utilizadas para lidar com os elementos causadores de sofrimento. Denota-se dessa compreensão que a estratégia de defesa implica uma ação consciente do indivíduo para lidar com o sofrimento que, por sua vez, permite ao estudioso perceber qual ou quais mecanismos inconscientes podem explicar a ação realizada em uma determinada situação. Por exemplo, a estratégia consciente de ir à igreja para pedir proteção divina frente a um problema vivenciado no trabalho pode suscitar o entendimento de que essa ação mobiliza o mecanismo inconsciente chamado de "deslocamento"; ou seja, a transferência de emoção associada a um objeto (organização) para outro (igreja), de modo que tal sentimento possa ser expressado sem colocar em risco a relação estabelecida pelo indivíduo com o objeto.

\section{METODOLOGIA}

Realizou-se uma pesquisa descritiva de abordagem qualitativa com o objetivo de compreender em profundidade as idiossincrasias (MINAYO, 2007) a respeito da psicodinâmica do trabalho de dez (10) médicos oncologistas atuantes em instituições de saúde, públicas e privadas, de Belo Horizonte. Os sujeitos da pesquisa foram selecionados por acessibilidade tendo em vista o tempo livre se mostrar exíguo na rotina dos profissionais.

O levantamento de dados ocorreu por meio de entrevista estruturada inspirada no Inventário de Trabalho e Riscos de Adoecimento (ITRA) de Mendes e Ferreira (2007), tendo sido adaptado para se transformar em um instrumento de abordagem qualitativa. Esses autores estabelecem que os riscos de adoecimento no trabalho devam ser investigados mediante a consideração de quatro (4) dimensões: 1) o contexto do trabalho, que avalia elementos pertinentes à forma como ele está organizado, às relações socioprofissionais e às condições nas quais as tarefas são executadas; 2) os danos físicos, psicológicos e sociais relativos ao trabalho; 3 ) o sentido do trabalho, correspondente às vivências de prazer e sofrimento experimentadas na realização do trabalho; 4) os custos físicos, cognitivos e afetivos do trabalho. O roteiro completo continha 25 questões, incluindo aquelas necessárias para a caracterização do perfil dos entrevistados.

A respeito do contexto de trabalho, no que tange ao modo como era organizado, o roteiro indagava aspectos associados ao ritmo e planejamento de trabalho, tempo disponível para a realização das tarefas e controle das atividades. Concernente às condições ocupacionais, eram avaliados itens relacionados ao ambiente físico, segurança no trabalho e instrumental disponibilizado para o exercício da função. Atinente às relações socioprofissionais apuravam-se elementos atrelados à integração, cooperação e comunicação dos oncologistas com os diferentes sujeitos envolvidos da prática oncológica, por exemplo, chefes, pares, profissionais da saúde e pacientes.

Quanto aos custos do trabalho, de um ponto de vista físico, era solicitado que os pesquisados opinassem sobre os esforços dispendidos para a realização das tarefas e, de um ponto de vista cognitivo, questionava-se a respeito da administração de problemas, imprevistos e desafios impostos pelo trabalho. Finalmente, de um ponto de vista afetivo 
averiguavam-se pontos vinculados ao controle das emoções, à ética e ao estado de espírito no trabalho.

Alusivo ao sentido do trabalho, referente ao prazer o roteiro avaliava tópicos sobre satisfação, expressão de ideias, realização profissional e reconhecimento no trabalho, enquanto pertencente ao sofrimento levantavam-se aspectos de insatisfação, sobrecarga, conflitos, constrangimentos e injustiças derivadas do fazer oncológico. Ao final, perguntavam-se quais eram as estratégias utilizadas para lidar com as situações potenciais ou causadoras de sofrimento ocupacional. Encerrando o roteiro, quesitos sobre danos ocupacionais foram colocados para explorar a existência de lesões ocorridas ao longo da atividade profissional, em uma perspectiva física e, sob o prisma psicossocial, questões foram formuladas sobre os conflitos decorrentes da vida privada versus vida ocupacional e o posicionamento sobre os resultados profissionais obtidos ao longo da carreira.

As entrevistas foram realizadas nos locais de trabalho dos médicos participantes do estudo. Elas foram gravadas e, após terem sido transcritas, passaram por um tratamento que recorreu à técnica de análise de conteúdo que tem por finalidade central fazer inferências a respeito do discurso atinente a determinado fenômeno. Ao utilizar essa técnica, o pesquisador usualmente adota como procedimento a apuração da frequência com que palavras, expressões e temas importantes aparecem nas falas, para assim possibilitar a identificação do conteúdo e das características das informações presentes no texto (FRANCO, 2008). A categorização é a última etapa da análise, consistindo na classificação dos elementos que exibem características comuns. As etapas antecedentes implicam a organização e a exploração do material. No caso do artigo aqui descrito, a fase da organização implicou a leitura flutuante do material coletado, procedimento que permitiu, em seguida, explorar e agrupar os dados para fins de categorizá-los nas unidades de registro definidas a priori (FRANCO, 2008), quais sejam as quatro dimensões estipuladas por Mendes e Ferreira (2007) para a avaliação dos riscos de adoecimento no trabalho, incluindo neste rol uma dimensão respeitante às estratégias de mediação do sofrimento ocupacional.

Para a definição das categorias de análise, ocorrida também em um procedimento estabelecido a priori por meio do uso da teoria, empregou-se como critério verificar a repetição de temas que emergiam com frequência no discurso de pelo menos 5 médicos entrevistados (Franco, 2008), reconhecendo-se que tal quantidade revelava características comuns para a maior parte dos participantes da pesquisa. Importa dizer que trechos das entrevistas foram utilizados para evidenciar as categorias estabelecidas, adiantando-se que eles devem ser considerados como uma representação individual de um coletivo de entrevistados e não como provas absolutas da realidade investigada (MINAYO; SANCHES, 1993).

\section{APRESENTAÇÃO E DISCUSSÃO DOS RESULTADOS}

O perfil dos médicos oncologistas pesquisados pode ser observado no Quadro 1. O Quadro 1 revela que a maioria dos pesquisados é do sexo masculino, tem idade acima de 31 anos, é casada, possui especialização completa, trabalha no emprego atual há pelo menos três anos, tendo em vista a exigência desse tempo de residência para o exercício da especialidade em oncologia e, trabalha 40 horas semanais na rede privada de saúde. 
Quadro 1: Perfil dos profissionais entrevistados

\begin{tabular}{|c|c|c|c|c|c|c|c|c|}
\hline Médico & Sexo & $\begin{array}{l}\text { Faixa } \\
\text { etária }\end{array}$ & $\begin{array}{c}\text { Estado } \\
\text { civil }\end{array}$ & Escolaridade & $\begin{array}{c}\text { Tempo } \\
\text { na } \\
\text { função }\end{array}$ & $\begin{array}{l}\text { Tempo na } \\
\text { instituição }\end{array}$ & $\begin{array}{c}\text { Carga } \\
\text { horária } \\
\text { semanal }\end{array}$ & $\begin{array}{c}\text { Esfera } \\
\text { de } \\
\text { atuação }\end{array}$ \\
\hline M1 & $M$ & 32 anos & Casado & $\begin{array}{c}\text { Especialização } \\
\text { Completa }\end{array}$ & 3 anos & 3 anos & $40 \mathrm{~h}$ & Privada \\
\hline $\mathrm{M} 2$ & $M$ & 36 anos & Casado & $\begin{array}{l}\text { Doutorado } \\
\text { Incompleto }\end{array}$ & 8 anos & 7 anos & $75 \mathrm{~h}$ & Privada \\
\hline M3 & $M$ & 30 anos & Solteiro & $\begin{array}{c}\text { Especialização } \\
\text { Completa }\end{array}$ & 4 meses & 4 meses & $40 \mathrm{~h}$ & Pública \\
\hline M4 & $\mathrm{F}$ & 43 anos & Casada & $\begin{array}{c}\text { Especialização } \\
\text { Completa }\end{array}$ & 11 anos & 8 anos & $40 \mathrm{~h}$ & Pública \\
\hline M5 & $M$ & $\begin{array}{c}43 \\
\text { anos }\end{array}$ & Casado & $\begin{array}{c}\text { Especialização } \\
\text { Completa }\end{array}$ & 10 anos & 3 anos & $40 \mathrm{~h}$ & Pública \\
\hline M6 & $M$ & 38 anos & Casado & $\begin{array}{c}\text { Mestrado } \\
\text { Incompleto }\end{array}$ & 4 anos & 5 anos & $60 \mathrm{~h}$ & Privada \\
\hline M7 & $M$ & 30 anos & Solteiro & $\begin{array}{c}\text { Especialização } \\
\text { Completa }\end{array}$ & 7 meses & 7 meses & $40 \mathrm{~h}$ & Privada \\
\hline M8 & $M$ & $\begin{array}{c}46 \\
\text { anos }\end{array}$ & Casado & $\begin{array}{c}\text { Especialização } \\
\text { Completa }\end{array}$ & 13 anos & 10 anos & $40 \mathrm{~h}$ & Privada \\
\hline M9 & $\mathrm{F}$ & 31 anos & Casada & $\begin{array}{c}\text { Especialização } \\
\text { Completa }\end{array}$ & 5 meses & 1 mês & $80 \mathrm{~h}$ & Privada \\
\hline M10 & $\mathrm{F}$ & $\begin{array}{c}32 \\
\text { anos }\end{array}$ & Casada & $\begin{array}{c}\text { Especialização } \\
\text { Completa }\end{array}$ & 5 meses & 4 meses & $49 \mathrm{~h}$ & Privada \\
\hline
\end{tabular}

Fonte: Dados da pesquisa

Destaca-se aqui a carga horária elevada de trabalho dos médicos entrevistados, reconhecendo-se aqui que uma jornada assim denota intensificação de trabalho, podendo conduzir o indivíduo ao adoecimento ocupacional futuro (MENDES; FERREIRA, 2007).

Neste caso, é razoável admitir que o trabalho médico deixe de ser uma atividade apenas autônoma, passando a se incorporar paulatinamente ao sistema de produção capitalista. Significa dizer que boa parte da categoria de médicos da atualidade se submete às regras desse sistema, desenvolvendo suas atividades em serviços públicos e privados. Como qualquer categoria que se sujeita a tais regras, torna-se uma mercadoria, diga-se de passagem, socialmente valorizada, porém suscetível às mazelas oriundas do trabalho em uma organização capitalista, a saber: a instabilidade no emprego; o ritmo intenso de trabalho; e a jornada prolongada, elementos que se somam às particularidades do trabalho médico oncológico de aliviar a dor e o sofrimento, assim como de conviver com a morte rotineiramente (LIMA JÚNIOR; CASTANHA, 2011; FLAUZINO, 2012; CANO, 2014; CANO; MORÉ, 2016).

As unidades de registro e as categorias de análise da pesquisa são apresentadas no Quadro 2. 
Quadro 2 - Unidades de registro e categorias da análise de conteúdo

\begin{tabular}{|c|c|}
\hline Unidades de Registro & \multirow{2}{*}{ Categorias } \\
\hline Contexto do Trabalho & \\
\hline Organização do trabalho & $\begin{array}{l}\text { Ritmo de trabalho } \\
\text {. Cobrança por resultados } \\
\text {. Planejamento do trabalho }\end{array}$ \\
\hline Condições do trabalho & $\begin{array}{l}\text { Ambiente do trabalho } \\
\text { Segurança do trabalho } \\
\text {. Instrumentos e equipamentos de trabalho }\end{array}$ \\
\hline Relações socioprofissionais & $\begin{array}{l}\text { Relacionamento entre profissionais } \\
\text { Trabalho em equipe } \\
\text {. Comunicação entre colegas e a chefia }\end{array}$ \\
\hline \multicolumn{2}{|l|}{ Custos do trabalho } \\
\hline Custo físico & . Esforços físicos \\
\hline Custo cognitivo & . Habilidades para resolver problemas \\
\hline Custo afetivo & . Controle das emoções \\
\hline \multicolumn{2}{|l|}{ Sentido do trabalho } \\
\hline Vivências de prazer & $\begin{array}{l}\text {. Realização no trabalho } \\
\text {. Liberdade para expressar opiniões } \\
\text {. Confiança entre colegas e chefes }\end{array}$ \\
\hline Vivências de sofrimento & $\begin{array}{l}\text { Esgotamento profissional } \\
\text {. Falta de organização no atendimento } \\
\text {. Insegurança no emprego } \\
\text {. Sobrecarga emocional }\end{array}$ \\
\hline Estratégias de mediação do sofrimento & $\begin{array}{l}\text { Atividades de lazer } \\
\text {. Apoio emocional }\end{array}$ \\
\hline \multicolumn{2}{|l|}{ Danos no trabalho } \\
\hline Danos psicossociais & $\begin{array}{l}\text { Conflitos familiares e sociais } \\
\text {. Perdas e ganhos profissionais }\end{array}$ \\
\hline
\end{tabular}

Fonte: Dados da pesquisa

Iniciando a descrição dos resultados pelas categorias do contexto pertinentes à forma como o trabalho está organizado, verificou-se que o ritmo de trabalho foi apontado pelos entrevistados como intenso e insuficiente para dedicar uma assistência mais cuidadosa e prolongada ao paciente. De um modo geral os médicos sinalizaram que esta deficiência decorre da agenda de atendimento que precisa ser despachada e que, invariavelmente, está preenchida com um número excessivo de pacientes.

O ritmo de trabalho intenso dificulta ao trabalhador ter condições de organizar o seu trabalho conforme as suas necessidades e os seus desejos, ressalvando-se que a adequação do tempo aos processos de trabalho é fundamental para o indivíduo vivenciar o prazer na execução de suas atividades (MENDES; FERREIRA, 2007). Trabalhar nessa condição geralmente acarreta sobrecarga do trabalhador, comprometendo o seu desempenho e contribuindo para o sentimento de improdutividade, incompetência e insatisfação (BENDASOLLI; SOBOLL, 2011). É apropriado enfatizar que o aumento da demanda e a superlotação dos hospitais contribuem para o agravamento desta realidade, trazendo como consequência o baixo número de unidades destinadas aos pacientes de média e alta complexidade (LIMA JÚNIOR; CASTANHA, 2011), exigindo também dos trabalhadores nessa condição dispender esforços muitas vezes superiores às suas possibilidades (FREITAS, 2012).

A cobrança por resultados, outra categoria da organização do trabalho, foi apontada como frequente na atividade dos médicos oncologistas, originando-se tanto dos pacientes e 
familiares, que demandam respostas a respeito da terapêutica adotada, quanto das instituições de saúde, que exigem produtividade dos profissionais. No tocante às instituições de saúde é oportuno comentar a queixa dos médicos de que precisam atender um número grande de pacientes, por vezes perturbando aliar a qualidade à produtividade no atendimento, fato que também sobrecarrega o profissional, conforme evidenciado anteriormente. Sobre isso cabe recorrer a Dejours (2012) quando o autor comenta que, para lidar com as imposições prescritas pela organização de trabalho, o trabalhador faz uso de sua inventividade, preenchendo e ultrapassando as inconsistências ocupacionais para, ao mesmo tempo, consolidar a prática de "quebra-galho" e se mostrar produtivo no exercício de suas funções.

Apesar de grande parte dos médicos entrevistados classificar o ritmo de trabalho como intenso e confirmar que é cobrada por resultados, também confessa que tal realidade se compensa, em parte, pela possibilidade de participação no planejamento do trabalho, não obstante ser obrigatório o cumprimento de normas e procedimentos pertinentes à condução do tratamento prestado aos pacientes. Um médico relatou que:

Existe um protocolo já pronto, mas fica a cargo de cada médico prescrever, ver se
tem indicação e se cabe dentro do protocolo, e quando a gente quer fazer alguma
coisa diferente e que não tem no protocolo, a gente tem a disponibilidade de ligar
para o chefe de serviço, discutir o caso e trocar alguma ideia. (M10)

Segundo Dejours (2011), a emancipação do indivíduo se inicia no momento em que ele não mais se sente confortável em ceder sua liberdade e manter-se atrelado a estruturas e processos organizacionais. Para resistir ao controle que emana da organização do trabalho (LALLEMENT, 2015), o indivíduo coloca à prova o seu grau de independência para se adequar às tarefas prescritas, fazendo uso da liberdade para conduzir as suas atividades (MAGGI, 2016). Acredita-se que a autonomia para planejar o trabalho tenha relação com a complexidade e a dinâmica das tarefas executadas pelo médico oncologista. Como o imponderável é corriqueiro na oncologia o especialista nessa área necessita fazer uso mais livre da inteligência prática e do conhecimento técnico para planejar o tratamento do paciente que está sob a sua responsabilidade, uma vez que a linha entre a vida e a morte é muito tênue no exercício da profissão oncológica (CANO; MORÉ, 2016).

Ainda sobre o contexto do trabalho é importante destacar que o ambiente físico, a segurança e os instrumentos utilizados na execução das tarefas foram apontados pelos médicos, de forma unânime, como elementos satisfatórios em termos das condições de trabalho que Ihes são oferecidas. Segundo comentou um médico:

... o ambiente é adequado porque temos em cada sala um computador, os móveis
necessários para o atendimento clínico, os prontuários estão disponíveis no
sistema eletrônico, nada é feito a mão, só de não ser feito a mão ajuda muito.
Considero as clínicas e os demais espaços bons e tranquilos. (M5)

Finalizando as categorias do contexto do trabalho, constatou-se pelo relato dos médicos oncologistas que as relações socioprofissionais são adequadas, notadamente porque parte significativa do trabalho realizado é executada em equipe. Além disso, os entrevistados afirmaram usufruir facilidade no acesso e na troca de informações, além de experimentar comunicação respeitosa com os pares, a chefia e outros profissionais da área de saúde. Argumenta-se que a cooperação se torna efetiva quando o desejo, o anseio e a vontade de colaborar se manifestam coletivamente, ressalvando-se que o respeito aos 
colegas de trabalho, bem como às regras profissionais e de segurança são adicionalmente importantes para o exercício colaborativo (DEJOURS, 2011; MENDES; MULLER, 2013). Nessa mesma linha de raciocínio Mendes e Ferreira (2007) dizem que as relações socioprofissionais, quando são contornadas pelo respeito, pela cooperação e pela solidariedade funcionam como fonte de superação do sofrimento no trabalho, principalmente no momento em que esse sofrimento se associa com a natureza da tarefa.

Quanto aos custos do trabalho, apurou-se que eles estão atrelados aos esforços físicos desempenhados no exercício das funções, às habilidades requeridas para resolver problemas e ao controle das emoções. Os médicos disseram não vivenciar problemas de ordem física, excetuando-se questões ergonômicas e de risco biológico pelo fato de lidarem com secreções dos pacientes. Quanto ao custo cognitivo sabe-se que imprevistos ocorrem no decorrer das atividades na oncologia e que as intercorrências vivenciadas exigem maior prontidão, não obstante a morte iminente do paciente resultar que o profissional não tenha controle sobre o prognóstico da doença (MAGER; ANDRYKOWSKI, 2002; SALANDER, 2002) ou experimente dificuldade para comunicar o diagnóstico (RODENBACH et al., 2016). Essa situação está bem caracterizada nas falas de dois oncologistas:

Direto, o dia inteiro, a gente fica com a cabeça morta. Pronto socorro também,
situações inusitadas, pacientes sem diagnósticos, pacientes graves, com risco
iminente de morte, exame laboratorial para sair, familiar cobrando, então o
desgaste emocional e cognitivo é o dia inteiro (M10).
Tem um colega que fala que todo dia cai um avião dentro do consultório do
oncologista, então acho que é mais ou menos por aí e você vai aprendendo a lidar
com isso. Muitas vezes o que vai acontecer com o nosso paciente está além do meu
controle, eu trato com um objetivo, mas muitas vezes o objetivo é prolongar o
tempo de vida, é aliviar o sofrimento. O fato do paciente morrer pela doença que
está avançada está fora do meu controle (M2).

Ainda sobre os custos do trabalho destacou-se o do tipo afetivo, emergindo daí a categoria pertinente ao controle das emoções. É importante apontar que os médicos oncologistas enfrentam situações de grande pressão e as perdas são intercorrências constantes no decorrer do seu trabalho, o que pode levar o profissional a desenvolver sentimentos de desgaste ou impotência (FLAUZINO, 2012). Essa condição foi destacada por um dos entrevistados:

Existem algumas situações que são marcantes pelo menos na minha experiência pessoal. A lida com as pessoas muito jovens é muito difícil, principalmente quando a gente tem o diagnóstico de pessoas jovens com câncer. Então existe esse desgaste de eu estar atendendo, estar cuidando de pessoas jovens que vão morrer. É muito triste ver o pai e uma mãe acompanhando o filho ou uma esposa sabendo que aquela pessoa não tem cura (M6).

No que se refere ao sentido do trabalho, evidenciaram-se como categorias associadas ao prazer ocupacional a realização no trabalho, a liberdade para expressar opiniões e a confiança entre colegas e chefia. O êxito no tratamento de uma doença, o reconhecimento dos pares e pacientes advindos da terapêutica empregada e as relações de coleguismo estabelecidas entre médicos, enfermeiros e chefia são elementos que explicam o prazer experimentado no exercício da função. As pessoas sentem necessidade de serem reconhecidas e, quando o desempenho é seguido de consequências positivas, passam a se sentir motivadas a trabalhar, principalmente no momento em que acreditam serem capazes 
de obter e realizar o que esperam do trabalho (DEJOURS, 2014). Sugere-se que a confiança seja fundamental no trabalho do médico oncologista, pois tal elemento e o risco inerente atrelado a esta profissão se entrelaçam, posto que no processo de tratamento é importante garantir a segurança do paciente (CANO; MORÉ, 2016). Conforme reforçam Dejours, Abdoucheli e Jayet (1994), a confiança permite que o trabalhador se reconheça no desenvolvimento do seu trabalho, servindo como um item que confere sentido positivo no que realiza.

O esgotamento profissional, a falta de organização no atendimento ao paciente, a insegurança no emprego e a sobrecarga emocional emergiram como categorias relativas ao sofrimento no trabalho. A falta de harmonia na realização das tarefas, o excesso de pacientes para fins de atendimento, a precarização da função do ponto de vista financeiro, inclusive levando o profissional a trabalhar em mais de um emprego, o cansaço decorrente da necessidade de trabalhar em três turnos e o estresse gerado pelo contato rotineiro com a vida e a morte de pacientes foram apontados pelos oncologistas como componentes de sofrimento ocupacional. Estes achados corroboram estudos realizados no ambiente brasileiro com profissionais da saúde (LIMA JÚNIOR; CASTANHA, 2011; FLAUZINO, 2012; CANO, 2014; CAMPOS; DAVID; SOUZA, 2014; BARROS; HONÓRIO, 2015; CANO; MORÉ, 2016; OLIVEIRA; CURY, 2016). Parte significativa dos itens evidenciados pela pesquisa está associada à organização do trabalho que, segundo comenta Dejours (2014), exerce uma ação sobre o aparelho psíquico do indivíduo, ao mesmo tempo em que ignora os projetos, as esperanças e os desejos do indivíduo trabalhador. Acredita-se que os elementos apontados pelos oncologistas não favoreçam a utilização da capacidade criativa que porventura poderiam demonstrar para ressignificar os impedimentos vivenciados no exercício da função. Ainda, tais elementos se credenciam a contribuir para o sofrimento se tornar patogênico e potencializar descompensações psíquicas e somáticas futuras.

Para lidar com as fontes potenciais de sofrimento no trabalho verificou-se que os médicos oncologistas fazem uso das atividades de lazer e da busca de apoio emocional dos pares de trabalho, da família e de amigos. Foi possível observar que tais estratégias de regulação parecem funcionar como um modo utilizado para abreviar o ciclo de execução de uma tarefa incessante, fatigante que, por vezes, pode parecer sem sentido, assim como uma via de evasão das pressões e dos conflitos reprimidos pertinentes ao ambiente ocupacional. Logo, o deslocamento e a sublimação parecem ser os mecanismos mais utilizados pelos entrevistados para transferir a compreensão dos problemas ocupacionais para instâncias não necessariamente atreladas à maneira como o trabalho está organizado. Ainda, as estratégias utilizadas pelos oncologistas são de cunho individual e não coletivo, portanto, não se mostrando eficazes para fins de modificação da forma como o trabalho está organizado, pois não contam com a adesão e a força do conjunto de profissionais. Funcionam apenas como uma proteção para suportar o sofrimento, não obstante ser argumentado que a defesa protetora se fundamentaria no mecanismo da racionalização (DEJOURS; ABDOUCHELI; JAYET, 1994; MORAES, 2013). Isso não se mostra totalmente infundado no caso estudado uma vez que os riscos inerentes à profissão, o ritmo intenso de trabalho, a cobrança por resultados foram adversidades apontadas com relativa normalidade pelos entrevistados, sugerindo que tais elementos devam também ser racionalizados como meio de proteção ao sofrimento. 
Por último, os conflitos familiares e sociais, bem como as perdas e ganhos profissionais estiveram entre as categorias mais frequentes nas falas dos médicos pesquisados acerca dos danos psicossociais decorrentes do trabalho que realizam. 0 depoimento de um médico é revelador no que concerne a essa situação:

A minha esposa é médica e mesmo ela sendo médica, ela não entende bem o excesso de trabalho, a ausência em casa, o cansaço físico. Às vezes você chega em casa exausto no final de semana e às vezes você opta por descansar ao invés de passear. As perdas realmente são perdas familiares, eu tenho muito medo de chegar ... meu filho tem cinco anos de idade, quando ele tiver 20 anos de idade eu perceber que eu não o acompanhei e que eu não o vi crescer, coisas que a gente ouve dos colegas, passou muito rápido, que não viu, que não acompanhou na escola, não acompanhou nos principais momentos (M6).

O depoimento acima revela que o espaço pessoal de vida do médico oncologista vem sendo tomado pela esfera do trabalho, significando dizer que o tempo e a energia direcionados para o desenvolvimento profissional impedem que estas qualidades sejam dedicadas à vida privada, impedindo o trabalhador de criar coletivos (BENDASOLLI, 2011) ou submetendo-o aos ditames mercadológicos (FRANCO; DRUCK; SELINGMANN-SILVA, 2010). Trata-se de um sequestro, uma invasão patrocinada pelo tempo de trabalho sobre os espaços pessoais de vida, por exemplo, aqueles relativos ao da família e do lazer (ENRIQUEZ, 1997; PERISTA; MAXIMIANO; FREITAS, 2000; BENDASOLLI, 2011).

Os elementos evidenciados pela análise de conteúdo permitem que a psicodinâmica do trabalho dos médicos oncologistas pesquisados possa ser esquematizada na figura 1.

Figura 1 - Psicodinâmica do trabalho de médicos oncologistas

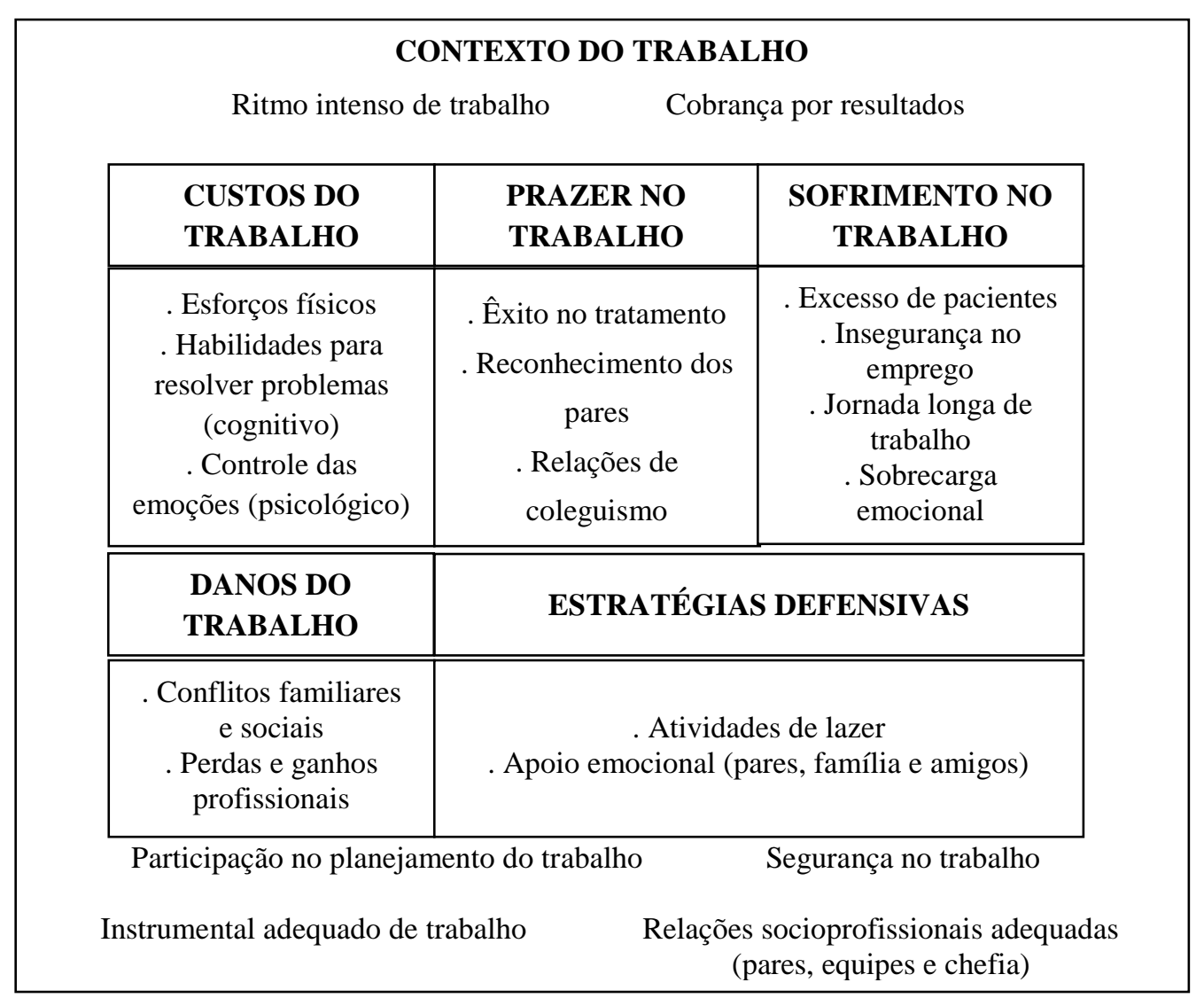

Fonte: Dados da pesquisa 
Conforme pode ser observado na Figura 1, elementos contextuais estruturantes caracterizam o trabalho dos oncologistas, a saber: participação no planejamento do trabalho, segurança do ambiente físico ocupacional, recursos técnicos satisfatórios disponibilizados para o exercício da função e relações socioprofissionais adequadas mantidas com a chefia, pares e equipe de trabalho. Todavia, elementos desestruturantes também contornam o trabalho dos oncologistas, que se mostra organizado por um ritmo intenso de atividade e pela cobrança por resultados. Em consonância com os pressupostos teóricos do artigo, enfatizou-se que a organização do trabalho pode surtir efeitos tanto favoráveis quanto desfavoráveis à saúde física e psíquica do trabalhador, levando-o a experimentar, indissociavelmente, vivências de prazer e sofrimento.

A inseparabilidade entre prazer e sofrimento manifestada pelo estudo evidencia que em um mesmo contexto de trabalho, por um lado, os oncologistas se sentem realizados profissionalmente ao obterem êxito no tratamento que dispendem ao paciente, são reconhecidos pelos pares e mantêm relações de coleguismo com a equipe de trabalho, incluindo chefia, pares e diferentes profissionais da área de saúde. Por outro lado, os oncologistas também se queixam do excesso de pacientes, da insegurança no emprego, da jornada longa de trabalho e da sobrecarga emocional. Esses elementos de sofrimento se somam aos custos físicos, cognitivos e afetivos decorrentes das funções que executam que realizam, notadamente alusivos: a questões de ordem ergonômica e biológica advindas de secreções dos pacientes; a imprevistos que exigem prontidão para lidar com a condução do tratamento do paciente e ao controle das emoções, uma vez que a vida e a morte são intercorrências corriqueiras no exercício da prática oncológica.

Os elementos de sofrimento igualmente se adicionam aos danos que a profissão acarreta, particularmente associados aos conflitos e as perdas vivenciadas fora da esfera de trabalho em razão de os médicos oncologistas não conseguirem equilibrar a vida pessoal com a profissional. Em consonância com a literatura sobre a psicodinâmica do trabalho, o sofrimento integra o ato de trabalhar e não deve ser eliminado sob pena de caso assim seja feito se retirar do trabalhador a capacidade de inventar ou criar uma solução para dirimir os conflitos derivados da relação entre os trabalhos prescrito e real.

Para fazer frente aos elementos que provocam a desestabilização psíquica motivada pela organização do trabalho, os oncologistas fazem uso de mecanismos compensatórios que não parecem favorecer uma mudança nas condições ocupacionais adversas, por exemplo, o envolvimento com atividades recreativas e a busca pelo apoio emocional de pares, família e amigos para a divisão das pressões advindas das atividades que realizam. São mecanismos que restabelecem a normalidade no trabalho, mas que não fazem os trabalhadores se emanciparem da realidade mobilizadora do sofrimento.

\section{CONSIDERAÇÕES FINAIS}

O estudo revelou que o ritmo funcional intenso e a cobrança por resultados foram elementos da organização do trabalho que podem desencadear riscos de adoecimento no trabalho dos médicos oncologistas, não obstante tal realidade se mostrar compensada por sentimentos afirmativos quanto às condições de realização das funções, por exemplo, associadas ao planejamento do trabalho e ao ambiente físico de atuação, que se mostra adequado, seguro e bem instrumentalizado. Somam-se a essa realidade itens positivos 
pertinentes às relações socioprofissionais no que dizem respeito à comunicação e ao relacionamento com a chefia e com outros profissionais da área da saúde.

Quanto aos custos no trabalho, os de natureza física não foram apontados como um problema para o desenvolvimento das atividades, pois isso faz parte da natureza da tarefa, o mesmo acontecendo com a dimensão cognitiva que requer habilidades para lidar com intercorrências e imprevistos inerentes à profissão oncológica. Vale ressaltar os custos de natureza afetiva que implicam a necessidade de controle das emoções, considerando que a perda é elemento recorrente na vida profissional do médico oncologista, não obstante tal vivência provocar sentimentos de desgaste e impotência. Quanto aos danos resultantes do trabalho, foram apontados os de natureza psicossocial relacionados aos conflitos familiares e sociais, como também às perdas e ganhos profissionais. Verificou-se que os danos dessa natureza prejudicam a interface entre a vida pessoal e a profissional dos participantes da pesquisa.

Conforme apontado pela literatura sobre o tema pesquisado, também esperado em termos de resultados, vivências de prazer e sofrimento perpassam de maneira indissociável a vida ocupacional dos médicos oncologistas. No que tange ao prazer, esta vivência se manifesta por meio da realização no trabalho, da liberdade para expressar opiniões e do relacionamento de confiança estabelecido entre pares e chefia. Quanto ao sofrimento no trabalho, ele se evidenciou por elementos associados ao esgotamento profissional, à falta de organização no atendimento ao paciente, à insegurança no emprego e à sobrecarga emocional. Visando o enfrentamento do sofrimento decorrente do trabalho, os médicos pesquisados fazem uso de estratégias individuais associadas ao apoio emocional (pares, família e amigos) e a fruição de atividades de lazer. São estratégias que não permitem a modificação dos elementos adversos da organização do trabalho, mas que protegem o psiquismo, mesmo que temporariamente. De qualquer forma, não obstante as estratégias utilizadas possam promover a adaptação ao trabalho, mantem-se o risco de agravarem o sofrimento que pretendiam evitar, conforme sustentado pela literatura.

Ainda que uma parte significativa das manifestações de sofrimento dos médicos entrevistados tenha se mostrado mais atrelada à profissão do que à organização do trabalho, reconhece-se que essa categoria paulatinamente está amarrada aos ditames do mercado de trabalho, inclusive se sujeitando atuar em diferentes instituições e turnos funcionais, seja para fins de sobrevivência ou para crescimento na carreira. A autonomia que outrora parecia ser um elemento distintivo na vida profissional de um médico, independentemente da sua especialidade de atuação, passa a ser controlada pela organização do trabalho uma vez que determinadas variáveis se introduziram no cotidiano funcional da categoria, por exemplo, o temor de erros clínicos e a preocupação com as questões subjetivas de pacientes e familiares frente ao diagnóstico e prognóstico das doenças. Elementos dessa natureza inserem a distinção entre o 'bom' e o 'mau' médico, como também se constituem em fontes potenciais de sofrimento e riscos de adoecimento no trabalho.

A contribuição acadêmica do artigo reside no fato de ele ter explorado uma categoria ocupacional pouco estudada no campo da psicodinâmica do trabalho, assim como por ter recorrido a uma abordagem qualitativa para captar as idiossincrasias do fenômeno estudado. Esse tipo de metodologia, por um lado, preencheu uma lacuna de pesquisa ao permitir que os dados colhidos fossem analisados em profundidade, tornando a compreensão do caso mais robusta. Por outro lado, não obstante o oncologista 
experimentar prazer na função que executa, o estudo evidenciou elementos contextuais de trabalho desestruturantes que o predispõem ao sofrimento e que, acompanhados dos danos e custos decorrentes do exercício, podem surtir efeitos desfavoráveis sobre a sua saúde física e psíquica, sob pena de o não equacionamento das disfunções organizativas apuradas prejudicar a qualidade do atendimento prestado ao paciente. É importante ressaltar que o estudo não tem a pretensão de alcançar generalidades, mas julga-se que analiticamente os resultados encontrados possam ser transferidos para outros contextos diferentes daqueles pertinentes aos hospitais e às clínicas oncológicas estudadas. Sugere-se que a pesquisa realizada e descrita no artigo seja ampliada com outras instituições oncológicas públicas e privadas no âmbito mineiro e nacional, inclusive de forma comparativa.

\section{REFERÊNCIAS}

ANTUNES, R. Os modos de ser da informalidade: rumo a uma nova era da precarização estrutural do trabalho? Serviço Social e Sociedade, São Paulo, v. 107, p. 405-419, jul./set. 2011. DOI: http://dx.doi.org/10.1590/S0101-66282011000300002.

BARROS; N. M. G. C.; HONÓRIO, L. C. Riscos de adoecimento no trabalho de médicos e enfermeiros em hospital regional mato-grossense. REGE - Revista de Gestão da USP, São Paulo, v. 22, n. 1, p. 21-39, 2015. DOI: https://doi.org/10.570/rege549.

BENDASOLLI, P. F. Mal-estar no trabalho: do sofrimento ao poder de agir. Revista Mal-Estar e Subjetividade, Fortaleza, v. XI, n. 1, p. 65-99, mar. 2011.

BENDASSOLLI, P. F.; ALVES, J. S. C.; TORRES, C. C. Inventário sobre significado do trabalho de profissionais de indústrias criativas. Avaliação Psicológica, Campinas, v. 13, n. 2. p. 177-186, 2014.

BENDASOLLI, P. F.; BORGES-ANDRADE, J. E. O significado do trabalho nas indústrias criativas. Revista de Administração de Empresas, São Paulo, v. 51, n. 2, p. 143-159, mar/abr. 2011. DOI: http://dx.doi.org/10.1590/S0034-75902011000200003.

BOYER, G. C. Sofrimento social e do trabalho no contexto da área "saúde mental e trabalho". Psicologia \& Sociedade, Belo Horizonte, v. 27, n. 1, p. 106-119, 2015.

BRUGNARA, E. S. S.; HONÓRIO, L. C. Vivências de prazer e sofrimento no trabalho de médicos oncologistas que atuam em hospitais de Minas Gerais. Encontro Nacional de Gestão de Pessoas e Relações de Trabalho. VI, 2017, Curitiba, PR. Anais... Curitiba: EnGPR, CD-ROM, 2017.

CAMPOS, J. L.; DAVID, H. M. S. L.; SOUZA, N. V. D. O. Prazer e sofrimento: avaliação de enfermeiros intensivistas à luz da psicodinâmica do trabalho. Escola Anna Nery Revista de Enfermagem, Rio de Janeiro, v. 18, n.1, p. 90-95, jan./mar. 2014. DOI: https://doi.org/10.5935/1414-8145.20140013. 
CANO, D. S. O médico entre a vida e a morte: um estudo psicológico em oncologia clínica. São Paulo: Casa do Psicólogo, 2014.

CANO, D. S.; MORÉ, C. L. O. O. Estratégias de enfrentamento psicológico de médicos oncologistas clínicos. Psicologia: Teoria e Pesquisa, Brasília, v. 32, n. 3, p. 1-10, jul./set. 2016. DOI: http://dx.doi.org/10.1590/0102-3772e323211.

CARVER, C. S.; SCHEIER, M. F. Autonomy and self-regulation. Psychological Inquiry, Oxford, v. 11, n. 4, p. 284-291, 2000. DOI: https://doi.org/10.2307/1449622.

CUNHA, M. R.; HONÓRIO, L. C. Psicodinâmica do trabalho de médicos oncologistas: vivências de prazer e sofrimento em instituições hospitalares da cidade de Belo Horizonte. Encontro Nacional de Pós-Graduação e Pesquisa em Administração. XLI, 2017, Rio de Janeiro, RJ.

Anais... Rio de Janeiro: EnANPAD, CD-ROM, 2017.

DEJOURS, C. Travail, souffrance et subjectivité. Sociologie du Travail, Paris, v. 42, n. 2, p. 329-340, 2000. DOI: https://doi.org/10.1016/s0038-0296(00)00111-4.

DEJOURS, C. Subjectivity, work, and action. Critical Horizons, London, v. 7, n. 1, p. 45-62, 2006. DOI: https://doi.org/10.1163/156851606779308161.

DEJOURS, C. Psicopatologia do trabalho: psicodinâmica do trabalho. Laboreal, Porto, v. 7, n. 1, p. 13-16, 2011.

DEJOURS, C. Psicodinâmica do trabalho e teoria da sedução. Psicologia em Estudo, Maringá, v. 17, n. 3, p. 363-371, jul/set. 2012.

DEJOURS, C. Work and self-development: the point of view of the psychodynamics of work. Critical Horizons, London, v. 15, n. 2, p. 115-130, 2014. DOI: https://doi.org/10.1179/1440991714z.00000000027.

DEJOURS, C.; ABDOUCHELI, E.; JAYET, C. Psicodinâmica do trabalho: contribuições da escola dejouriana à análise da relação prazer, sofrimento e trabalho. São Paulo: Atlas, 1994.

DEJOURS, C.; DERANTY, J. P. The centrality of work. Critical Horizons, London, v. 11, n. 2, p. 167-180, 2010. DOI: https//doi.org/10.1558/crit.v11i2.167.

DERANTY, J. F. Historical objections to the centrality of work. Constellations, New York, v. 22, n. 1, p. 105-121, 2015. DOI: https://doi.org/10.1111/1467-8675.12141.

DUARTE, F. S.; MENDES, A. M. Da escravidão à servidão voluntária: perspectivas para a clínica psicodinâmica do trabalho no Brasil. Farol - Revista de Estudos Organizacionais e Sociedade, v. 2, n. 3, p. 68-128, abril. 2015. DOI: https://doi.org/10.25113/farol.v2i3.2579.

ENRIQUEZ, E. A organização em análise. Petrópolis: Editora Vozes, 1997. 
FLAUZINO, C. J. O que acontece no encontro do médico com a morte do seu paciente. 2012, 157 f. Dissertação (Mestrado em Psicologia) - Universidade de São Paulo, Instituto de Psicologia, São Paulo, 2012.

FRANCO, M. L. P. B. Análise de conteúdo. Brasília: Líber Livro, 2008.

FRANCO, T.; DRUCK, G.; SELIGMANN-SILVA, E. As novas relações de trabalho, o desgaste mental do trabalhador e os transtornos mentais no trabalho precarizado. Revista Brasileira de Saúde Ocupacional, São Paulo, v. 35, n. 122, p. 229-248, jul./dez. 2010. DOI: http://dx.doi.org/10.1590/S0303-76572010000200006.

FREITAS, L. G. Centralidade do Trabalho. In: VIEIRA, F. O; MENDES, A. M; MERLO, A. R.C. (Orgs.). Dicionário crítico de gestão e psicodinâmica do trabalho. Curitiba: Juruá, 2013.

GAULEJAC, V. Approche socioclinique de la souffrance au travail. International Review of Sociology, Oxford, v. 18, n. 3. p. 433-441, November 2008. DOI: https://doi.org/ 10.1080/03906700802376495.

GERNET, I. Actualités de la recherche en psychodynamique du travail. Annales Médicopsychologiques, Paris, v. 174, n. 7; p. 602-605, 2016. DOI: https://dx.doi.org/ 10.1016/j.amp.2016.05.005.

HIRSCHFELD; R. R.; FEILD, H. S. Work centrality and work alienation: distinct aspects of a general commitment to work. Journal of Organizational Behavior, New Jersey, v. 21, p. 789200, 2000. DOI: http://doi.org/10.1002/1099-1379(200011)21:7<789::aid-job59>3.0.co;2-w.

INSTITUTO NACIONAL DE CÂNCER JOSÉ ALENCAR GOMES DA SILVA - INCA. Estimativas de incidência e mortalidade por câncer no Brasil. Rio de Janeiro: INCA, 2016.

KUBO, S. H.; GOUVÊA, M. A. Análise dos fatores associados ao significado do trabalho. Revista de Administração, São Paulo, v. 47, n. 4, p. 540-554, out./nov./dez. 2012. DOI: https://doi.org/10.5700/rausp1057.

LALLEMENT, M. Work and the challenge of autonomy. Social Science Information, Canada, v. 54, n. 2, p. 229-248, 2015. DOI: https://doi.org/10.1177/0539018414566423.

LASCAR, P. Souffrance et risques psychosociaux au travail. European Psychiatry, Paris, v. 29, n. 8, p. 628-629, 2014. DOI: https://doi.org/10.1016/j.eurpsy.2014.09.127.

LIMA JÚNIOR, J. H.; CASTANHA, A. L. B. O trabalhador médico: prazer e dor como ofício. Encontro Nacional de Pós-Graduação e Pesquisa em Administração. XXXV, 2011, Rio de Janeiro, RJ. Anais... Rio de Janeiro: EnANPAD, CD-ROM, 2011.

MAGER, W. M.; ANDRYKOWSKY, M. A. Communication in the cancer 'bad news' consultation: patient perceptions and psychological adjustment. Psycho-Oncology, Chester, v. 11, p. 35-46, 2002. DOI: https://doi.org/10.1002/pon.563. 
MAGNUS, C. N.; MERLO, A. R. C. Sofrimento-prazer: dinâmica do trabalho de profissionais de saúde mental de um hospital psiquiátrico público. Psico, Porto Alegre, v. 43, n. 2, 185-192, abr./jun. 2012.

MARTINS, A. A. V.; HONÓRIO; L. C. Prazer e sofrimento docente em uma instituição de ensino superior privada em Minas Gerais. Revista Organizações e Sociedade, Salvador, v. 21, n. 68, p. 835-852, jan./mar. 2014.

MENDES, A. M.; FERREIRA, M. C. Inventário sobre Trabalho e Riscos de Adoecimento - ITRA: instrumento auxiliar de diagnóstico de indicadores críticos no trabalho. In: MENDES, A. M. B. Psicodinâmica do trabalho: teoria, método e pesquisas. São Paulo: Casa do Psicólogo, 2007.

MENDES, A. M.; MULLER, T. C. Prazer no trabalho. In: VIEIRA, F. O.; MENDES, A. M.; MERLO, A. R. C. (Orgs.). Dicionário crítico de gestão e psicodinâmica do trabalho. Curitiba: Juruá, 2013.

MINAYO, M. C. S. O desafio do conhecimento: pesquisa qualitativa em saúde. São Paulo: Hucitec, 2007.

MINAYO, M. C. S.; SANCHES, O. Quantitativo-qualitativo: oposição ou complementaridade? Cadernos de Saúde Pública, Rio de Janeiro, v. 9, n. 3, p. 239-262, jul./set. 1993.

MORAES, R. D. Estratégias defensivas. In: VIEIRA, F. O., MENDES, A. M.; MERLO, A. R. C. (Orgs.). Dicionário crítico de gestão e psicodinâmica do trabalho. Curitiba: Juruá, 2013.

MORIN, E. M. Os sentidos do trabalho. Revista de Administração de Empresas, São Paulo, v. 41, n. 3, p. 8-19, jul./set. 2001. DOI: http://dx.doi.org/10.1590/S0034-75902001000300002.

OLIVEIRA, A. E. G.; CURY, V. E. Cuidar em oncologia: uma experiência para além do sofrimento. Memorandum: Memória e História em Psicologia, Belo Horizonte, v. 31, p. 237258, out. 2016.

PERISTA, H.; MAXIMIANO, S.; FREITAS, F. Família, gênero e trajetórias de vida: uma questão de (usos do) tempo. IV Congresso Português de Sociologia, Coimbra, Portugal. Anais... Coimbra, 2011.

POLOMENI, A. La question du sens au travail en instituition hospitalière. Psyco-Oncologie, Paris, v. 9, n. 1, p. 19-25, 2015. DOI: https://doi.org/10.1007/s11839-015-0501-y.

RODENBACH, R. A.; RODENBACH, K. E.; TEJANI, M. A.; EPSTEIN, R. M. Relationships between personal attitudes about death and communication with terminally ill patients: how oncology clinicians grapple with mortality. Patient Education and Counseling, Ireland, v. 99, n. 3, p. 356-363, 2016. DOI: https://doi.org/10.1016/j.pec.2015.10.010. 
RODRIGUES, S. J. A.; HONÓRIO, L. C. Prazer e Sofrimento: vivências de médicos oncologistas do Hospital Santa Casa de Belo Horizonte. Encontro Nacional de Pós-Graduação e Pesquisa em Administração. XL, 2016, Rio de Janeiro, RJ. Anais... Rio de Janeiro: EnANPAD, CD-ROM, 2016.

SALANDER; P. Bad News from the patient's perspective: an analysis of the written narratives of newly diagnosed cancer patients. Social Science \& Medicine, Boston, v. 55, p. 721-732, 2002. DOI: https://doi.org/10.1016/s0277-9536(01)00198-8.

SHANAFELT, T.; DYRBYE, L. Oncologist burnout: causes, consequences, and responses. Journal of Clinical Oncology, Boston, v. 30, n. 11, p. 1235-1245, April 2012. DOI: https://doi.org/10.1200/JCO.2011.39.7380.

SHARABI, M.; HARPAZ, I. Improving employees' work centrality improves organizational performance: work events and work centrality relationships. Human Resource Development International, Oxford, v. 13, n. 4, p. 79-392, September 2010. DOI: https://dx.doi.org/10.1080/13678868.2010.501960.

SILVA, A.; GONÇALVES, M.; ZONATTO, V. C. S. Determinantes de prazer e sofrimento no trabalho hospitalar: uma análise à luz da teoria da psicodinâmica do trabalho. Base - Revista de Administração e Contabilidade da Unisinos, São Leopoldo, v. 14, n. 3, p. 197-212, julho/setembro, 2017. DOI: https://doi.org/0.4013/base.2017.143.04.

SIMÕES, D. A. P. Prazer e sofrimento no trabalho de médicos oncologistas que atuam em unidades hospitalares mineiras. 2016, 108 f. Dissertação (Mestrado em Administração) Faculdade Novos Horizontes, Belo Horizonte, 2016.

TOLFO, S. R.; PICCININI, V. Sentidos e significados do trabalho: explorando conceitos, variáveis e estudos empíricos brasileiros. Psicologia \& Sociedade, Porto Alegre, v. 19, Edição Especial 1, p. 38-46, 2007. 